\title{
Combining Radar and Rain Gauge Rainfall Estimates for Flood Forecasting: A Case Study in The Jinzu River Basin, Japan
}

\author{
Danang Dwi ADMOJO1*, Taichi TEBAKARI² and Mamoru MIYAMOTO ${ }^{3}$ \\ ${ }^{1}$ Student member of JSCE, Graduate School of Engineering, Toyama Prefectural University \\ (Kurokawa 5180, Imizu, Toyama 939-0398, Japan) \\ *E-mail:t657001@ @st.pu-toyama.ac.jp \\ ${ }^{2}$ Member of JSCE, Department of Environmental Engineering, Toyama Prefectural University \\ (Kurokawa 5180, Imizu, Toyama 939-0398, Japan) \\ E-mail:tebakari@pu-toyama.ac.jp \\ ${ }^{3}$ Member of JSCE, ${ }^{3}$ International Center for Water Hazard and Risk Management (ICHARM) \\ (1-6 Minamihara, Tsukuba, Ibaraki 305-8516, Japan) \\ E-mail:mmiyamoto@pwri.go.jp
}

\begin{abstract}
Radar rainfall estimates are widely used for real-time flood forecasting. An effective and accurate early warning system, with the assistance of radar rainfall estimates and hydrological modelling, is vital for reducing the effects of flood related-hazards. Detailed spatial and temporal data on the distribution of rainfall over a wide range area can be provided by weather radar. However, rainfall data captured at a single point location remains inaccurate. The combination of two datasets, radar and ground gauges, therefore constitutes the optimal method to estimate rainfall in a river basin.

This study evaluated the rainfall data-combining technique of conditional merging $(\mathrm{CM})$ in the Jinzu River Basin. This was then applied as the rainfall input for flood forecasting. A distributed hydrological model, developed by the International Center for Water Hazard and Risk Management (ICHARM) known as the Integrated Flood Analysis System (IFAS), was established and applied to evaluate the performance of the $\mathrm{CM}$ method for flood forecasting relative to the original radar simulations. Numerous cases with two sets of input data (radar and conditional methods) were tested during the period of 2011-2014. Here, the CM method was evaluated, and the applicability of a distributed model to flood forecasting in the Jinzu River Basin was quantitatively examined.
\end{abstract}

Key Words : Radar rainfall estimates, conditional merging, distributed hydrologic model, flood forecasting

\section{INTRODUCTION}

Rainfall measurements are essential for the application of hydrological models. Ground gauges and weather radar are widely used for acquiring near-real time estimates of rainfall accumulation ${ }^{1}$. Hydrological models rely on rain gauges to accurately record catchment rainfall. Rain gauges can provide direct rainfall estimates at a point location, but are not able to provide detailed spatial information regarding rainfall ${ }^{2}$. Rainfall distribution from rain gauges is normally estimated by speculating a spatial geometry, such as a Thiessen polygon, inverse distance squared weighting, or a kriging technique. However, these estimations do not accurately reflect how rain actually falls ${ }^{3}$.
There are alternatives to making conventional rainfall observations with ground gauges. In particular, weather radar can produce quantitative precipitation information, with higher spatial (a few km) and temporal (hourly) resolution compared to traditional ground gauges ${ }^{4}$. The ability of radar rainfall data to provide spatial information overcomes any shortage in ground gauge data. While weather radar cannot accurately capture rainfall amounts at a given location, a rain gauge is ideally suited to this purpose. Hence, combining both radar and ground gauge data could enable accurate estimation of rainfall5). The Japan Meteorological Agency (JMA) has introduced a precipitation nowcasting system called the Radar-AMeDAS network, generated from the radar rainfall and adjusted using a high-density 


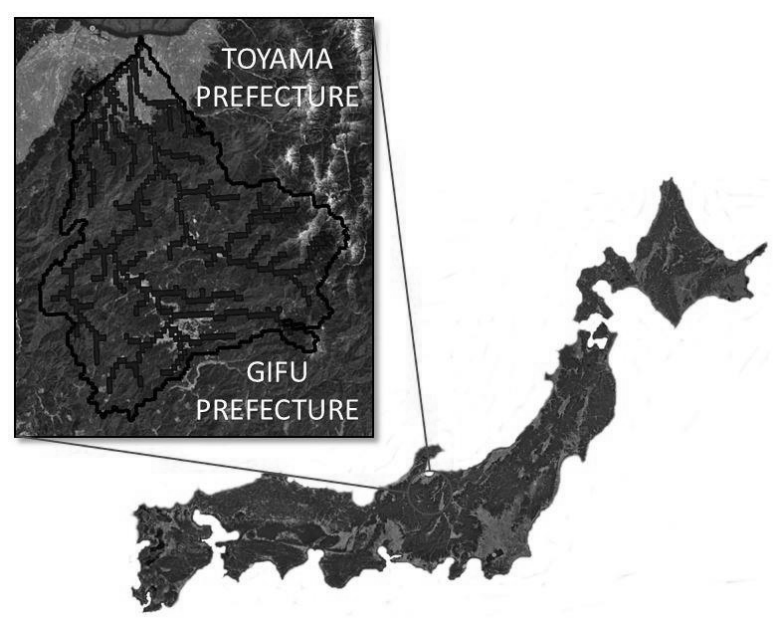

Fig.1 The Jinzu River Basin (Copyright Google Earth).

gauge network from the Automated Meteorological Data Acquisition System (AMeDAS). Radar echo intensity data are spatially particularized over a wide area. Calibration considering echo intensities of radar is managed to suit surface observation data on a range area as quantitative precipitation estimation.

Numerous methods have been proposed to merge and adjust rain gauge and radar measurements to acquire more appropriate rainfall accumulation data, including co-kriging677), statical objective analysis ${ }^{8}$, and Kalman filtering9). However, some of these techniques are extremely time consuming. Goudenhoofdt and Dellobe (2009) ${ }^{10}$ ) examined various methods of combining radar and rain gauge data, including mean field bias correction, range-dependent adjustment, statical local bias correction and range-dependent adjustment, Brandes spatial adjustment, ordinary kriging, kriging with radar-based error correction and kriging with external drift. They concluded that the application of kriging interpolation produced the best result. Therefore, in this study, radar and rain gauge data were combined by kriging with radar-based error correction.

This study evaluated rainfall using the conditional merging (CM) method in the Jinzu River Basin. In addition, the applicability of rainfall data to regional flood forecasting following CM was also examined. For this purpose, a grid-based distributed hydrology model was established and calibrated as the conceptual modelling tool, and several cases were evaluated from $2011-2014$.

\section{STUDY AREA}

The Jinzu River Basin (Fig. 1), located approxi-

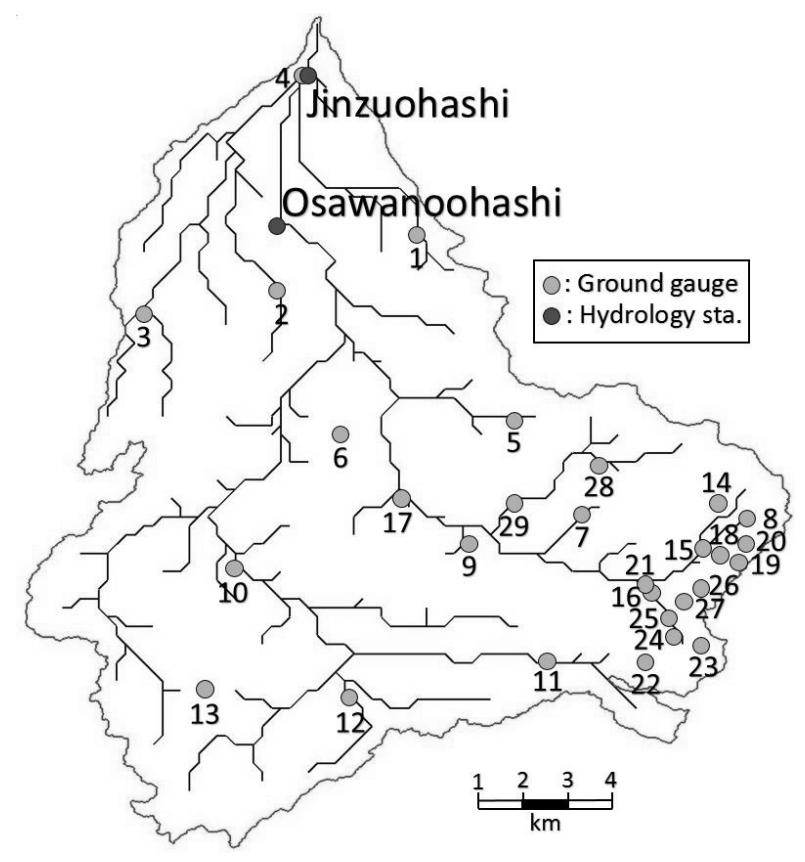

Fig. 2 Ground gauges and hydrology stations in the Jinzu River Basin.

mately at the center of the Sea of Japan and Toyama Prefecture, was selected as the target area of this study. The total area of Jinzu River Basin is approximately $2,720 \mathrm{~km}^{2}$, and the elevation ranges from 200 to $2,000 \mathrm{~m}$. The basin borders the Sho River Basin to the east and the Joganji River Basin to the west. The main stream of the Jinzu River, which is the longest river in Toyama Prefecture, stretches for $120 \mathrm{~km}$, and flows from Mount Kaore in Gifu Prefecture to Toyama Bay and the Sea of Japan on the north side. The upper river basin is mostly occupied by natural forest and some parts are herbaceous with sparse vegetation, while residential areas, paddy field, and cropland stretch from the foot of the mountains to the river mouth.

The Jinzu River basin was the subject of this study due to its economic significance and history of flood events in recent decades. Furthermore, Toyama's administrative center, and a large urban area, are located along the Jinzu River. Thus, it is necessary to establish an adequate flood forecasting system for this area.

\section{DATA AND METHODOLOGY}

\section{(1) Rain gauge data}

Hourly rainfall data were available from 29 ground gauges, which were installed and operated by the Ministry of Land, Infrastructure, Transportation, and Tourism (MLIT) of Japan, as shown by the green 
Table 1 Characteristics of radar $^{12)}$.

\begin{tabular}{|cll|}
\hline No & \multicolumn{1}{c|}{ Details } & \\
\hline 1 & Operator & JMA \\
2 & Spatial resolution & $1 \mathrm{~km}$ \\
3 & Time interval & $10 \mathrm{~min}$ \\
4 & Data distribution & $5-10 \mathrm{~min}$ \\
5 & Cover area & $120 \mathrm{~km}$ radius \\
6 & Wave lenght & $5-6 \mathrm{~cm}$ \\
\hline
\end{tabular}

circles in Fig. 2. The data is freely available and can be conveniently downloaded from the MILT water information system ${ }^{11}$.

\section{(2) Hydrology station}

The MLIT has two measurement discharge stations (Jinzuohashi and Osawanoohashi), which are indicated by the red circles in Fig. 2. These hydrology stations provide information such as hourly water level and observed discharge for the Jinzu River, for use as watershed management and disaster prevention tools.

\section{(3) Radar rainfall data}

The radar observation system in Japan is managed by the JMA and MLIT. The JMA radar network consists of $20 \mathrm{C}$-band radars that monitor the rainfall amount and distribution over most of Japan. The characteristics of C-band radar are given in Table 1. The MLIT has developed a new radar observation network, the X-band multi-parameter radar network, specifically for flash flood observations. Since the first network was announced in 2009, the MLIT has organized a further $37 \mathrm{X}$-band MP radar networks ${ }^{12}$. Unfortunately, due to its limited observation range, the X-band MP radar network is unable to cover all of the Jinzu River Basin. Therefore, only the C-band radar network was used in this study.

\section{(4) Method for combining radar and rain gauge data}

The method for combining radar and rain gauge data was referred to as "conditional merging" by Sinclair and Pegram (2015) ${ }^{13)}$. The CM method was devised by Ehret (2002) ${ }^{14)}$ and Pegram (2002) ${ }^{15}$. The method adopts the radar field to determine and correct the error associated with ordinary kriging based on rain gauge data. The CM process is described in Fig. 3.

a) The rainfall field was observed at discrete points by rain gauges.

b) The precipitation data from the rain gauges were kriged at the radar grid resolution to obtain the best linear unbiased estimate of rainfall.

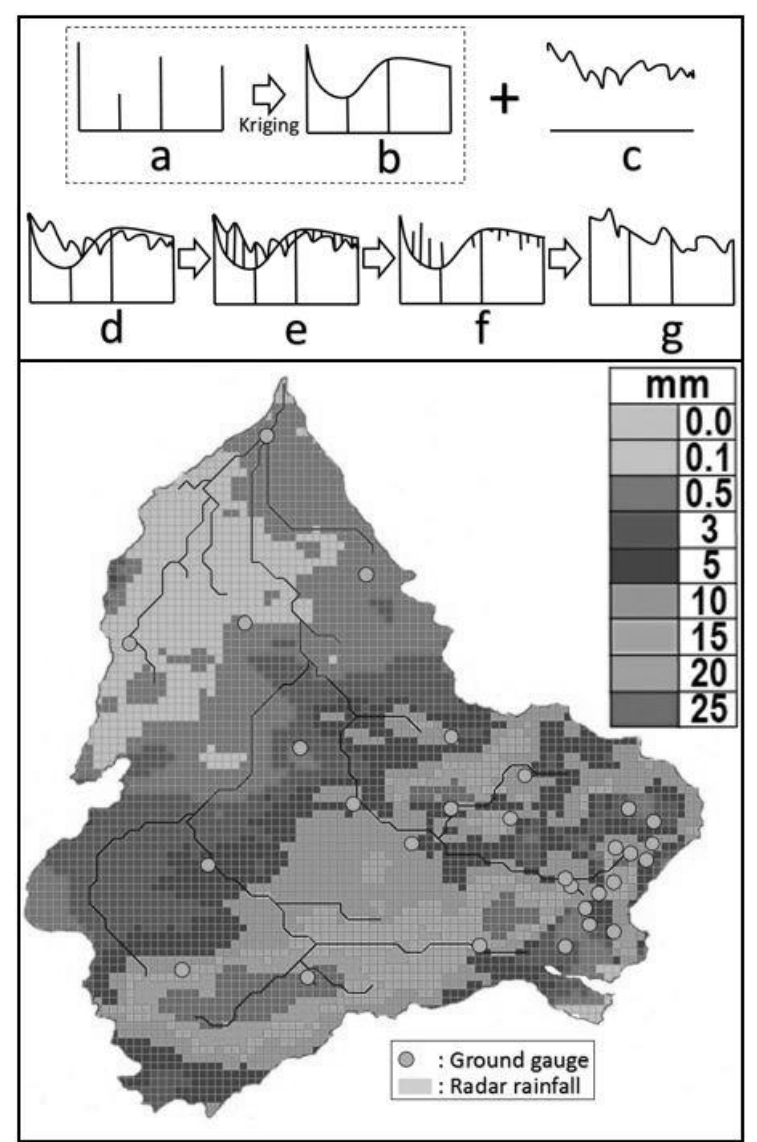

Fig. 3 The conditional merging $(\mathrm{CM})$ process (bottom: imagine of hourly radar rainfall ${ }^{13)}$.

c) The rainfall field was also observed by radar on a regular, volume-integrated grid.

d) The radar pixel values at the rain gauge locations were interpolated onto the radar grid using Kriging. e) At each grid point, the deviation $\mathrm{C}$ between the observed and interpolated radar value was computed. f) The field of deviations obtained from e) was applied to the interpolated rainfall field obtained from Kriging the rain gauge observations.

g) A rainfall field was obtained that followed the mean field of the rain gauge interpolation, while preserving the mean field deviations and the spatial structure of the radar field.

The error structure of the merged estimate was assessed using these formulas:

$$
\begin{gathered}
Z(s)=G k(s)+\varepsilon g(s) \\
R(s)=R k(s)+\varepsilon r(s) \\
M(s)=G k(s)+\varepsilon r(s) \\
E[Z(s)-M(s)]=E[\varepsilon g(s)-\varepsilon r(s)] \\
\operatorname{var}[Z(s)-M(s)]=\operatorname{var} E[\varepsilon g(s)-\varepsilon r(s)] \\
=\sigma^{2} \varepsilon g(s)+\sigma^{2} \varepsilon r(s)-2 \operatorname{cov}[\varepsilon g(s), \operatorname{cr}(s)] \\
=\beta-2 \sigma \varepsilon g(s) \rho
\end{gathered}
$$




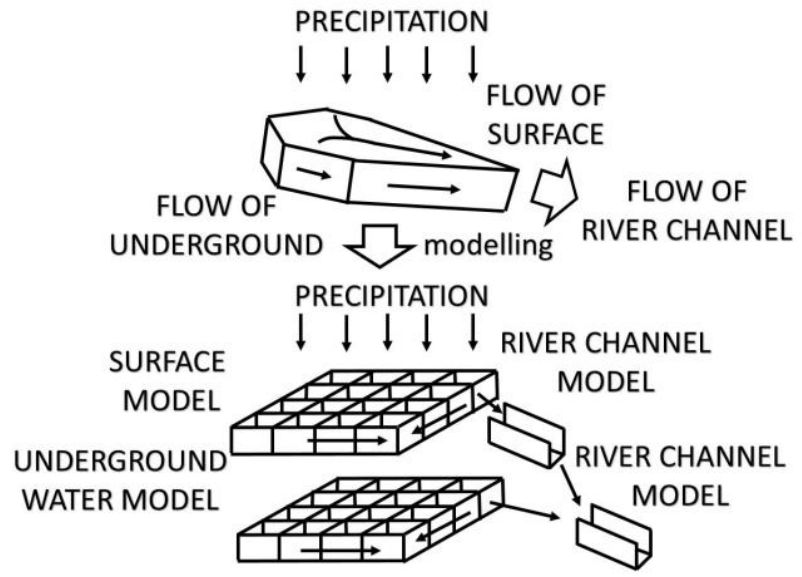

Fig. 4 Outline of the Integrated Flood Analysis System (IFAS) model $^{16)}$

$$
\begin{aligned}
& \varepsilon g(s)=Z(s)+G k(s) \\
& \varepsilon r(s)=R(s)+R k(s) \\
& \beta=\sigma^{2} \varepsilon g(s)+\sigma^{2} \operatorname{cr}(s)
\end{aligned}
$$

where $\mathrm{Z}(\mathrm{s})$ is the true rainfall field at location $\mathrm{s}$, $\mathrm{Gk}(\mathrm{s})$ is the kriged (mean field) estimate of $\mathrm{Z}(\mathrm{s})$ from the rain gauge data, $R(s)$ is the radar rainfall estimate, $\mathrm{Rk}(\mathrm{s})$ is the kriged (mean field) estimate of $\mathrm{R}(\mathrm{s})$ using the radar values at rain gauge locations, and $\mathrm{M}(\mathrm{s})$ is the merged estimate of $\mathrm{Z}(\mathrm{s})$.

The term $\operatorname{gg}(\mathrm{s})$ in equation (1a) is unknown because $\mathrm{Z}(\mathrm{s})$ is unknown. In equation (1b), $\operatorname{cr}(\mathrm{s})$ is known and, on the basis that $\mathrm{R}(\mathrm{s})$ is a measurement of $\mathrm{Z}(\mathrm{s})$, Equation (1c) can be used to estimate $\mathrm{Z}(\mathrm{s})$. Equation (1d) shows that the expected value of the error between the merged estimate and the true field is zero if the fields are Gaussian, because the kriged estimates are unbiased in this case. The variance of the error estimate given by equation (1e) can be decomposed, as shown in equation (1f). The variance of the error is (trivially) zero at the gauged points, while at any other position in the field, it is bounded by a maximum value of $\beta$. The positive correlations $\rho$ between $\operatorname{\varepsilon g}(\mathrm{s})$ and $\operatorname{cr}(\mathrm{s})$ are strongly (positively) correlated, as expected, because both gauges and radar are measurements of $\mathrm{Z}(\mathrm{s})$. The variance of the error will thus be significantly less than $\beta$, as suggested by equation $(1 \mathrm{~g})$.

\section{(5) Distributed hydrological model}

The International Center for Water Hazard and Risk Management (ICHARM), under the auspices of the United Nations Educational, Scientific and Cultural Organization (UNESCO), has developed an Integrated Flood Analysis System (IFAS) as a toolkit for more effective and efficient flood forecasting. IFAS can use either ground gauge or radar and sat-

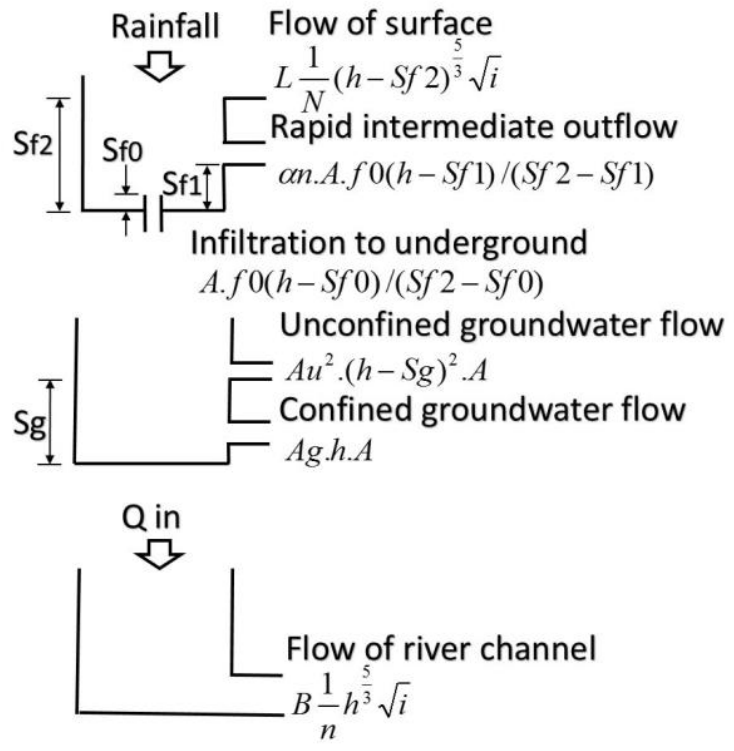

Fig.5 Conceptual structure of the IFAS model ${ }^{16)}$

ellite-based rainfall, as well as geographic information system (GIS) functions to create river channel network. In brief, IFAS incorporates the following features: an additional geospatial data import function, automatic downloading of satellite data, function for importing and calculating rainfall data, and a function for exporting rainfall distribution and river discharge data as a Google Earth-based presentation. In addition, IFAS has been used to provide information on insufficiently gauged river basin ${ }^{17)}{ }^{18)}$.

IFAS operates the Public Works Research Institute Distributed Hydrologycal Model (PDHM) as its runoff simulation model. The PDHM model accommodates the configuration of two tanks (surface and underground) in the vertical direction and a third tank in the form or the river channel. An outline of the IFAS model and its conceptual structure are shown in Figs. 4 and 5, respectively. Where, $S_{f 2}, S_{f 1}$, $S_{f 0}$ are the respective heights at surface, intermediate, ground infiltration flow occurs, $S_{g}$ is the height at which unconfined groundwater occurs, $h$ is the storage height for the model, $L$ is mesh length, $N$ is Manning's roughness coefficient, B is the breadth of river channel, and $\alpha \mathrm{n}, \mathrm{f0}, \mathrm{Au}, \mathrm{Ag}$ is coefficients.

\section{HYDROLOGY EVALUATION}

The validation process was conducted by comparing rainfall from the ground gauge measurements, radar observations, and $\mathrm{CM}$ method by considering the bias, correlation coefficients (CCs), and root mean square error (RMSE). 
Table 2 Comparison of hourly rainfall with ground rainfall. $\mathrm{CCs}$, correlation coefficient; CM, conditional merging; RMSE, root mean square error.

\begin{tabular}{|cccccc|}
\hline Period & $\begin{array}{c}\text { Rainfall } \\
\text { data }\end{array}$ & $\begin{array}{c}\text { Total } \\
\text { precipitation } \\
(\mathrm{mm})\end{array}$ & BIAS & CCs & $\begin{array}{c}\text { RMSE } \\
\text { (mm/ } \\
\text { hour) }\end{array}$ \\
\hline $22 / 05 / 2011-$ & radar & 271.3 & 0.166 & 0.782 & 0.056 \\
$07 / 06 / 2011$ & CM & 238.2 & 0.075 & 0.948 & 0.023 \\
$03 / 07 / 2011-$ & radar & 107.6 & 0.226 & 0.339 & 0.202 \\
$10 / 07 / 2011$ & CM & 157.0 & 0.097 & 0.941 & 0.062 \\
$18 / 08 / 2011-$ & radar & 326.4 & 0.257 & 0.561 & 0.146 \\
$29 / 08 / 2011$ & CM & 312.0 & 0.152 & 0.903 & 0.062 \\
$20 / 09 / 2011-$ & radar & 209.2 & 0.188 & 0.814 & 0.121 \\
$26 / 09 / 2011$ & CM & 204.0 & 0.082 & 0.972 & 0.056 \\
$10 / 07 / 2012-$ & radar & 168.4 & 0.291 & 0.449 & 0.226 \\
$16 / 07 / 2012$ & CM & 147.6 & 0.142 & 0.863 & 0.086 \\
$18 / 03 / 2014-$ & radar & 177.7 & 0.124 & 0.650 & 0.034 \\
$10 / 04 / 2014$ & CM & 195.0 & 0.048 & 0.946 & 0.012 \\
$13 / 08 / 2014-$ & radar & 299.5 & 0.321 & 0.492 & 0.194 \\
$24 / 08 / 2014$ & CM & 259.5 & 0.154 & 0.892 & 0.071 \\
\hline
\end{tabular}

Table 3 Comparison of accumulated ground rainfall with radar and $\mathrm{CM}$ rainfall. CM, conditional merging.

\begin{tabular}{|lccc|}
\hline Period & $\begin{array}{c}\text { Duration } \\
\text { (days) }\end{array}$ & $\begin{array}{c}\text { Rainfall } \\
\text { data }\end{array}$ & $\begin{array}{c}\text { Accumulated rainfall } \\
\text { comparison }\end{array}$ \\
\hline $22 / 05 / 2011-$ & 17 & radar & -0.332 \\
$07 / 06 / 2011$ & & CM & -0.155 \\
$03 / 07 / 2011-$ & & radar & 0.222 \\
$10 / 07 / 2011$ & 8 & CM & -0.102 \\
$18 / 08 / 2011-$ & & radar & -0.221 \\
$29 / 08 / 2011$ & 12 & CM & -0.156 \\
$20 / 09 / 2011-$ & & radar & -0.076 \\
$26 / 09 / 2011$ & 7 & CM & -0.038 \\
$10 / 07 / 2012-$ & & radar & -0.380 \\
$16 / 07 / 2012$ & 7 & CM & -0.208 \\
$18 / 03 / 2014-$ & & radar & -0.027 \\
$10 / 04 / 2014$ & 23 & CM & -0.139 \\
$13 / 08 / 2014-$ & & radar & -0.381 \\
$24 / 08 / 2014$ & 12 & CM & -0.207 \\
\hline
\end{tabular}

The performance of IFAS model was evaluated using three error indicators, the wave shape error $\left(E_{w}\right)$, volume error $\left(E_{v}\right)$, and peak discharge error $\left(E_{p}\right)$, which are defined by the Japan Institute of Construction Engineering (JICE). A Smaller error gives a better model. The error formula is given below.

$$
\begin{aligned}
& E_{W}=\frac{1}{n} \sum_{i=1}^{n}\left[\left(Q_{0(i)}-Q_{c(i)}\right) / Q_{0(i)}\right]^{2} \\
& E_{V}=\left[\left(\sum_{i=1}^{n} Q_{0(i)}-\sum_{i=1}^{n} Q_{c(i)}\right) / \sum_{i=1}^{n} Q_{0(1)}\right]
\end{aligned}
$$

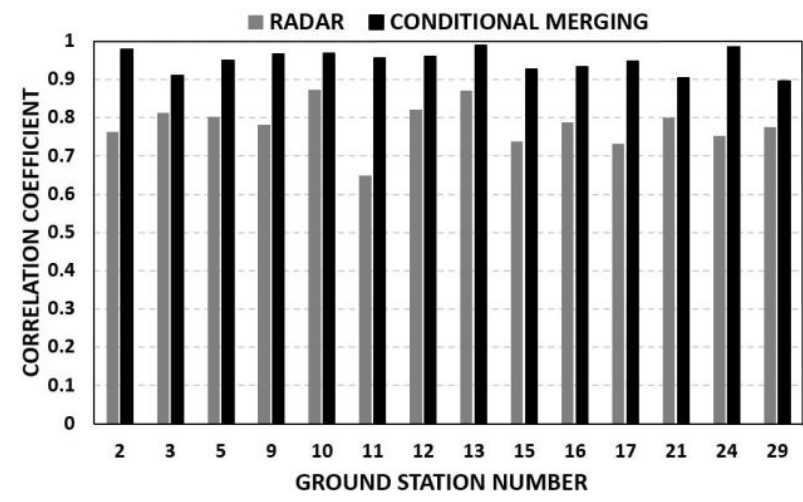

Fig.6 A comparison of the CCs for rainfall data from radar and CM (22/05/2011-07/06/2011).

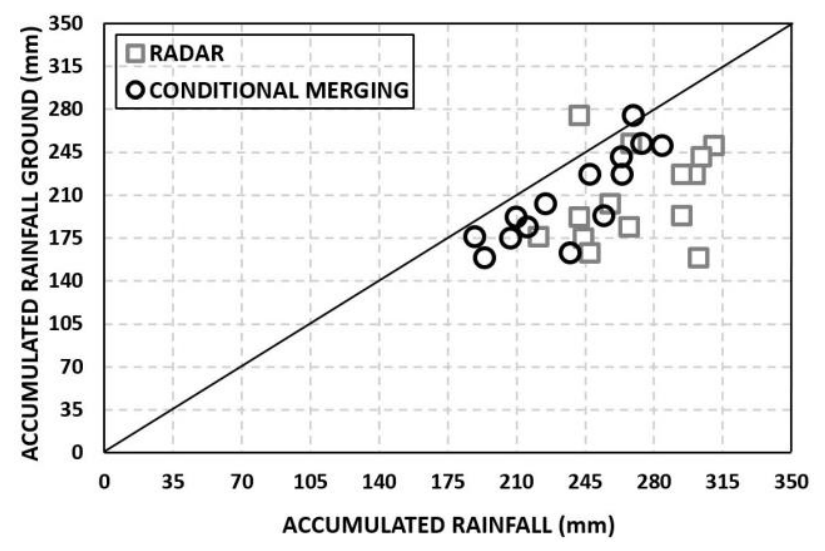

Fig.7 Accumulated ground rainfall comparison with radar and CM (22/05/2011-07/06/2011). CM, conditional merging.

$$
E_{P}=\left(Q P_{0}-Q P_{c}\right) / Q P_{0}
$$

where, $n$ is the number of calculations, $Q_{o(i)}$ is the observed discharge at time $i, Q_{c(i)}$ is the calculated discharge at time $i, Q P_{o}$ is the maximum observed discharge, $Q P_{c}$ is the maximum calculated discharge.

\section{RESULTS AND DISCUSSION}

\section{(1) Rainfall comparison}

During several representative periods from 2011 to 2014, rainfall data from weather radar and the CM method were compared with ground gauge data at the locations of individual gauges. Table 2 shows the results of a statistical assessment of the point-scale gauge data, and indicates contrasts in the data throughout the study period. The CCs for the relationship between radar and ground gauge data ranged from 0.339 to 0.814 . In general, the results indicate that the use of radar data produced a huge bias in the estimation of rainfall in terms of point-scale observations. When applying the merging technique, the 
Table 4 Simulation result at Osawanoohashi Station. CM, conditional merging; Ew, wave shape error; Ev, volume error; Ep, peak discharge error.

\begin{tabular}{|lcccc|}
\hline \multicolumn{1}{|c}{ Period } & $\begin{array}{c}\text { Rainfall } \\
\text { data }\end{array}$ & Ew & Ev & Ep \\
\hline $22 / 05 / 2011-$ & radar & 0.155 & -0.091 & 0.261 \\
$07 / 06 / 2011$ & CM & 0.067 & 0.066 & 0.011 \\
$03 / 07 / 2011-$ & radar & 0.130 & 0.244 & -0.240 \\
$10 / 07 / 2011$ & CM & 0.060 & -0.020 & 0.021 \\
$18 / 08 / 2011-$ & radar & 0.298 & -0.498 & -0.137 \\
$29 / 08 / 2011$ & CM & 0.375 & -0.295 & 0.263 \\
$20 / 09 / 2011-$ & radar & 0.054 & 0.036 & 0.126 \\
$26 / 09 / 2011$ & CM & 0.088 & 0.086 & 0.286 \\
$10 / 07 / 2012-$ & radar & 0.244 & -0.003 & -0.006 \\
$16 / 07 / 2012$ & CM & 0.098 & 0.151 & 0.248 \\
$18 / 03 / 2014-$ & radar & 0.191 & 0.433 & -0.334 \\
$10 / 04 / 2014$ & CM & 0.204 & 0.461 & -0.485 \\
$13 / 08 / 2014-$ & radar & 0.457 & -0.065 & -0.127 \\
$24 / 08 / 2014$ & CM & 0.191 & 0.182 & 0.331 \\
\hline
\end{tabular}

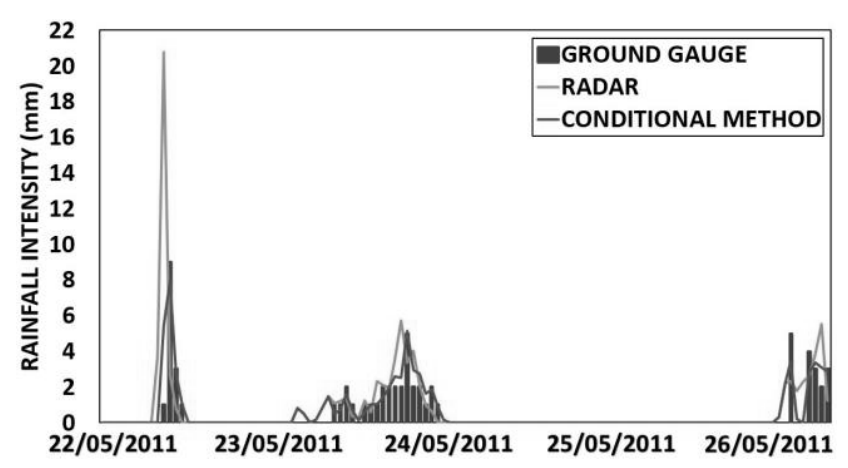

Fig.8 The improvement in the visualization of the rainfall data at station number 11 (22/05/2011-26/05/2011).

$\mathrm{CC}$ values were greater than 0.85 , which indicated a strong relationship with ground gauge data. In all cases, there was a decrease in the RMSE when using $\mathrm{CM}$ rather than just the original radar data.

For hourly rainfall and accumulated rainfall, to determine the CCs among ground gauges, original radar, and the CM method at point-scale, we used an example from the period of 22/05/2011-07/06/2011, which is shown in Figs. 6 and 7. In fact, there are 29 ground gauges available, but due to a lack of data for this period, only 14 ground gauges could be used. The location of the ground gauge is shown in Fig. 2. It was found that the CCs and accumulated rainfall estimate improved when the CM method was applied. The cumulative rainfall comparison estimated by radar and the CM method are shown in Table 3. It was found that for accumulated rainfall, both radar and $\mathrm{CM}$ tended to produce a negative bias (i.e., overestimation of rainfall). However, radar and CM delivered reasonable estimates of accumulated rainfall. For total rainfall, radar estimation had a bias
Table 5 Simulation result at Jinzuohashi Station. CM, conditional merging; Ew, wave shape error; Ev, volume error; Ep, peak discharge error.

\begin{tabular}{|lcccc|}
\hline Period & $\begin{array}{c}\text { Rainfall } \\
\text { data }\end{array}$ & Ew & Ev & Ep \\
\hline $22 / 05 / 2011-$ & radar & 0.086 & 0.071 & 0.132 \\
$07 / 06 / 2011$ & CM & 0.080 & 0.182 & -0.039 \\
$03 / 07 / 2011-$ & radar & 0.170 & 0.341 & -0.255 \\
$10 / 07 / 2011$ & CM & 0.093 & 0.104 & -0.030 \\
$18 / 08 / 2011-$ & radar & 0.200 & -0.266 & -0.026 \\
$29 / 08 / 2011$ & CM & 0.113 & -0.128 & 0.205 \\
$20 / 09 / 2011-$ & radar & 0.068 & 0.156 & 0.014 \\
$26 / 09 / 2011$ & CM & 0.128 & 0.244 & 0.156 \\
$10 / 07 / 2012-$ & radar & 0.250 & 0.072 & 0.039 \\
$16 / 07 / 2012$ & CM & 0.138 & 0.192 & 0.255 \\
$18 / 03 / 2014-$ & radar & 0.183 & 0.420 & -0.282 \\
$10 / 04 / 2014$ & CM & 0.218 & 0.469 & -0.471 \\
$13 / 08 / 2014-$ & radar & - & - & 0.260 \\
$24 / 08 / 2014$ & CM & - & - & 0.407 \\
\hline
\end{tabular}

value less than 0.40 , whereas CM had a smaller bias of not more than 0.25 . The improvement in the visualization of the rainfall data is shown in Fig. 8. Here, the hourly radar rainfall intensity was improving, although the $\mathrm{CM}$ method was used for comparison with the ground rainfall at station number 11 (for details of the location, see Fig. 2).

\section{(2) Flood forecasting with IFAS}

Two types of rainfall data (original radar and $\mathrm{CM}$ method) were used as inputs to IFAS to calculate river discharge in the Jinzu River Basin. The simulated discharge was related to observed discharge at the hydrology station to evaluate the performance of the IFAS model (the Ew, Ev, and Ep) using original radar data and the $\mathrm{CM}$ method.

Overall, radar-based simulation yielded reasonable results at both Osawanoohashi and Jinzuohashi stations. More specifically, Fig. 9 shows the simulation at these hydrology stations using rainfall data pairs for the period of 22/05/2011-07/06/2011. Although the IFAS model produced the discharge values that were too high (see Tables 4 and 5; Ep: 0.261 at Osawanoohashi station and 0.132 at Jinzuohashi station), the remaining indocators had lower errors, the wave shape error (Ew) was 0.155 and 0.086 , and the volume error $(\mathrm{Ev})$ was -0.091 and 0.071 , respectively, for Osawanoohashi and Jinzuohashi stations. For CM method-based simulation, in most cases the results were acceptable in comparison to the observed discharge. It can be seen from Fig. 9 that the simulation for the period of 22/05/2011-07/06/2011 was excellent, with an Ep below 5\% (see Tables 4 and 5) at both stations. Additional error indexes, i.e., 

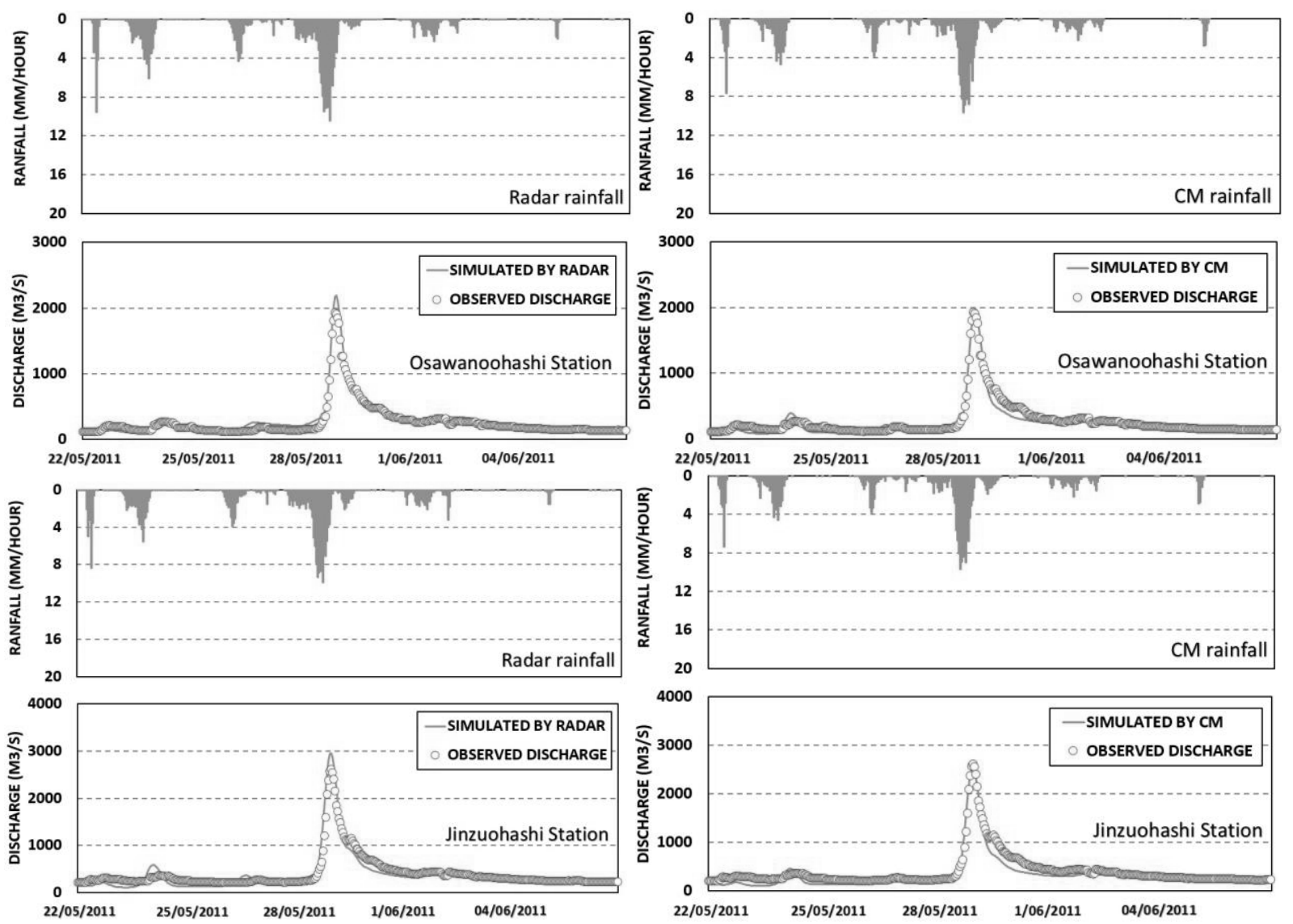

Fig.9 Simulation for the period of 22/05/2011-07/06/2011 at Osawanoohashi station (top) and Jinzuohashi station (bottom).
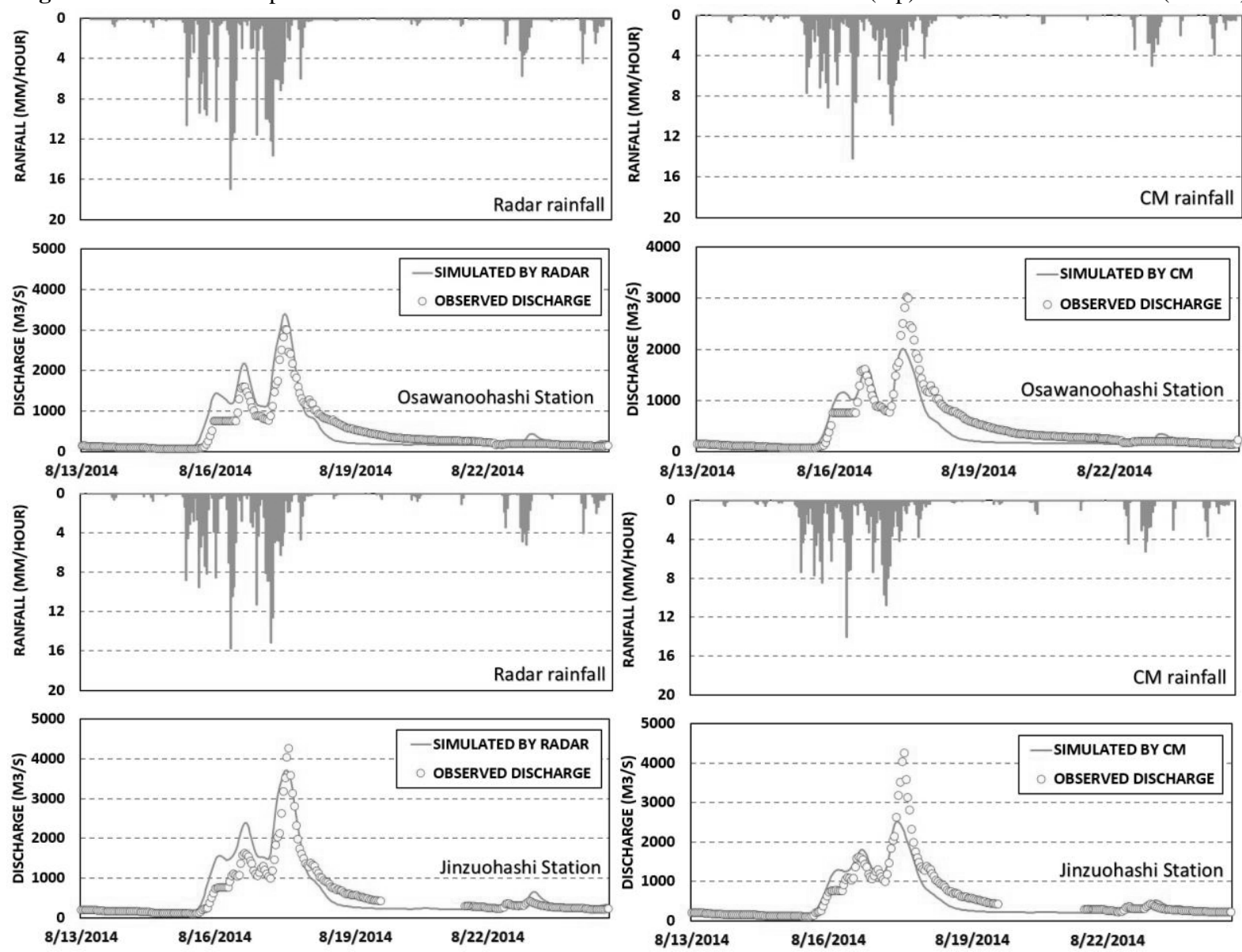

Fig.10 Simulation for the period of 13/08/2014-24/08/2014 at Osawanoohashi station (top) and Jinzuohashi station (bottom). 
the $\mathrm{Ew}(0.067 ; 0.080)$ and $\mathrm{Ev}(0.066 ; 0.182)$, also produced satisfactory results for the Osawanoohashi and Jinzuohashi stations, respectively.

During the simulation period, a few unsatisfactory results were obtained when using the radar- and CM method-based methods, particularly in 2014. A detailed estimate for the period of 13/08/2014-24/08/2014 is given in Fig. 10. The Ew of the radar-based simulation was large (0.457), whereas the CM method-based simulation was just 0.191. In terms of Ep, the radar-based simulation was superior to the CM method-based simulation at Osawanoohashi station. When the two simulation results were combined, the changes in land use from 2011 to 2014 clearly had an influence. The IFAS model was extremely sensitive with regard to the land use parameter. Unfortunately, due to lack of observation data, error indicators could not be estimated at the Jinzuohashi station for the period of 13/08/2014-4/08/2014. According to the statistical analysis, the CM method-based simulation was sometimes less accurate than the radar analysis. This was due to the fact that the CM rainfall was dependent on the ground rainfall. The number of ground rainfall data points used in the simulation, together with the changes in land use, probably decreased the accuracy. Moreover, the complexity of the discharge pattern, e.g., the number of peaks, also appeared to influence the accuracy of the simulation. The simulation based on the CM method generally matched well with a simple hydrograph (see Fig. 9) but found it difficult to imitate a complicated hydrograph, although it was still able to mimic the shape (see Fig. 10) depending on the spatial information supplied by radar. This indicates that radar can provide additional valuable information to assist in capturing the spatial design of flood.

The rising period, time, and peak discharge are the most crucial parameters for flood forecasting. The rainfall distribution and intensity significantly affect the peak flow. Simulation with the IFAS used radar and CM-based rainfall, and present an appropriate peak time and the rising part of the peak to calculate the measurement flow. Furthermore, the main peak discharge error differed by less than $30 \%$ between the two hydrology stations, using both radar and CM-based rainfall data from 2011-2012 for the simulation (see Tables 4 and 5). However, a large error in the peak flow was observed for 2014, particularly in the CM-based simulation. An example is shown in Fig. 10, although able to reproduce the first peak, there is significant deviation in the main peak discharge.

Tables 4 and 5 give the three error indicators for the simulation using two sets of rainfall input for several periods from 2011 to 2014 at the Osawanoohashi and Jinzuohashi stations. It can be seen that radar- and CM method-based simulations performed well compared with observation data.

\section{CONCLUSIONS}

Weather radar rainfall data typically lacks accuracy at the point-scale. It was found that for hourly rainfall, the CCs for the relationship between radar and ground gauged data varied from 0.33 to 0.81 . However, radar rainfall data was better able to represent total rainfall in comparison with ground gauge rainfall data, with a bias less than 0.40 .

The objective of this study was to apply and evaluate the CM method for radar and rain gauge data, and assess the performance of the different rainfall data in flood forecasting in the Jinzu River Basin. CM was initially used to combine radar and rain gauge data. It was concluded that in comparison to ground gauge data, the merged rainfall data sources were an improvement based on the 24-h rainfall $\mathrm{CCs}$ and the reduced RMSE. In addition, accumulated rainfall estimates were improved by the use of CM. The merged rainfall data were used as inputs to a distributed hydrology model (IFAS). By comparing the model outputs with observations at hydrology stations, it was apparent that despite a few unsatisfactory results, especially in 2014, the IFAS model using radar-based and CM method-based simulations frequently produced results that were comparable to measured data.

\section{REFERENCES}

1) Sene, K. : Flash flood: forecasting and warning, Chapter 2: Precipitation measurement. pp. 33-67, 2013.

2) Steenbergen, V. N. and Willems, P. : On the added value of radar data in hydrological modelling and flood forecasting, International Conference on Hydroinformatics, 2014.

3) Kim, B. S., Hong, J. B., Kim, H. S. and Yoon, S. Y. : Combining radar and rain gauge estimates for flood forecasting using conditional merging method, World Environmental and Water Resources Congress 2007: Restoring Our Natural Habitat, 2007.

4) Berne, A. and Krajewski, W. F. : Radar for hydrology: unfulfilled promise or unrecognized potential?, Advance in Water Resources 51, 2013.

5) Pettazi, A. and Salson, S. : Combining radar and rain gauges rainfall estimates using conditional merging: a case study, The Seventh European Conference On Radar in Meteorology and Hydrology, 2012.

6) Krajewski, W. F. : Cokriging of radar-rainfall and rain gage data, Jurnal of Geophysical Research Atmosphered, Vol. 92, pp. 9571-9580, 1987.

7) Sun, X., Mein, R. G., Keenan, T, D., and Elliot, J. F. : Flood 
estimation using radar and rain gauge data, Jurnal of Hydrology, Vol. 239, pp. 4-18, 2000.

8) Pereira Fo., A. J., Crawfrod, K. C., and Hartzell, C. L. : Improving WSR-88D hourly rainfall estimates, Weather Forecast, Vol. 13, pp. 1016-1028, 1998.

9) Todini, E. : A Bayesian technique for conditioning radar precipitation estimates to rain-gauge measurements, $\mathrm{Hy}$ drology and Earth Sciences Discussion European Geosciencies Union, Vol. 5, pp. 187-199, 2001.

10) Water Information System, Ministry of Land, Infrastructure, Transport, and Tourism, Online access at: http://www1.river.go.jp, 2017

11) Goudenhoofdt, E. and Delobbe, L. : Evaluation of radar-gauge merging methods for quantitative precipitation estimates, Hydrology and Earth Sciences, Vol. 13, pp. 195-203, 2009.

12) Nakakita, E. and Kim, S. : Recent application of weather radar observation into hydrologic forecasting in Japan, Proceedings of the International Symposium on Flood Research and Management, 2015.

13) Sinclair, S. and Pegram, G. : Combining radar and rain gauge rainfall estimates using conditional merging, Atmospheric Science Letter, Vol. 6, pp. 19-22, 2015.

14) Ehret, U. : Rainfall and flood nowcasting in small catch- ments using weather radar, Phd Thesis, University of Stuttgart, 2002.

15) Pegram, G. G. S. : Spatial interpolation and maping of rainfall: 3, Progress Report to The Water Research Commision for the period April 2001 to March 2002, 2002.

16) Technical Note of PWRI No.4148, ICHARM Publication no. 14, Integrated Flood Analysis System (IFAS) version 1.2 user's manual, June 2009.

17) Miyamoto, M., Ono, M., Nabesaka, S., Okazumi, T., and Iwami, Y. : Applicability of a flood forecasting method utilizing global satellite information to an insufficiently-gauged river basin: a case of a river basin in the Philippines, Proceedings of $10^{\text {th }}$ International Conference on Hydroinformatics, IWA IAHR, No. 1395, Aug. 2014.

18) Miyamoto, M., Sugiura, A., Okazumi, T., Tanaka, S., Nabesaka, S., and Fukami, K : Suggestion for an advanced early warning system based on flood forecasting in Bengawan Solo river basin, Indonesia, Proceedings of $10^{\text {th }} \mathrm{In}$ ternational Conference on Hydroinformatics, IWA IAHR, No. 394, July 2012.

(Received April 7, 2017) 